TRILOGI: Jurnal Penelitian Ilmu Sosial dan Eksakta Volume: 1, Nomor 1, 2021, Hal: 17-26

\title{
Dampak Pelatihan Kerja, Lingkungan Kerja, Dan Kompensasi Terhadap Kinerja Karyawan
} (Studi Pada PT. Perkebunan Nusantara X Ajung di Jl. MH. Thamrin Ajung)

\author{
Bachtiar Apriyanto*, Feti Fatimah, Nursaidah \\ Universitas Muhammadiyah Jember; bachtiarapriyanto12345@gmail.com, fetifatimah@unmuhjember.ac.id, \\ nursaidah@unmuhjember.ac.id
}

\begin{abstract}
Abstrak: Penelitian ini bertujuan untuk mengetahui dan menganalisis dampak pelatihan kerja, lingkungan kerja dan kompensasi terhadap kinerja karyawan. Jenis penelitian deskriptif kuantitatif dengan menggunakan metode purposive sampling dengan sampel 76 responden. Variabel yang digunakan dalam penelitian ini terdiri dari variabel bebas yaitu pelatihan kerja X1, lingkungan kerja X2, kompensasi X3. Variabel terikat adalah kinerja karyawan Y. Alat uji yang digunakan adalah regresi linier berganda, dengan perangkat lunak SPSS versi 22.00. Hasil analisis menggunakan regresi linier berganda yaitu: $\mathrm{Y}=3,636+0,662 \mathrm{X} 1+0,304 \mathrm{X} 2+0,481 \mathrm{X} 3$. Hasil uji t didapat nilai signifDOI: https://doi.org/ 10.47134/trilogi.v1i1.4 ikansi sebesar 0,000 $(0,000<0,05)$ menunjukkan pelatihan kerja ber${ }^{*}$ Correspondensi: Bachtiar Apriyanto Email: bachtiarapriyanto12345@gmail.com

Received: 21 Juli 2021

Accepted: 03 Agustus 2021

Published: 30 September 2021 pengaruh signifikan terhadap kinerja karyawan. Variabel lingkungan kerja menunjukkan nilai signifikansi $0,000(0,000<0,05)$, artinya variabel lingkungan kerja berpengaruh signifikan terhadap kinerja karyawan. Variabel kompensasi menunjukkan nilai signifikansi $0,000(0,000<0,05)$, sehingga variabel kompensasi berpengaruh terhadap kinerja karyawan pada PTPN X Kebun Ajung Gayasan Jember. Nilai R square sebesar 0,719 berarti besarnya pengaruh variabel bebas terhadap variabel terikat adalah $71,9 \%$ dan sisanya $28,1 \%$.
\end{abstract}

Copyright: () 2021 by the authors. Submitted for possible open access publication under the terms and conditions of the Creative Commons Attribution (CC BY) license (http://creativecommons.org/licenses/by/4.0/).

Kata kunci: Pelatihan Kerja, Lingkungan Kerja, Kompensasi, Dan Kinerja Karyawan.

Abstrak: This study aims to determine and analyze the impact of job training, work environment and compensation on employee performance. This type of quantitative descriptive research using purposive sampling method with a sample of 76 respondents. The variables used in this study consisted of independent variables, namely job training $X 1$, work environment $\mathrm{X} 2$, compensation X3. The dependent variable is employee performance $Y$. The test instrument used is multiple linear regression, with SPSS software version 22.00. The results of the analysis using multiple linear regression are: $Y=3.636+0.662$ $\mathrm{X} 1+0.304 \mathrm{X} 2+0.481 \mathrm{X} 3$. The results of the t-test obtained a significance value of $0.000(0.000<0.05)$ indicating job training has a significant effect on employee performance. The work environment variable shows a significance value of $0.000(0.000<0.05)$, meaning that the work environment variable has a significant effect on employee performance. The compensation variable shows a significance value of $0.000(0.000<0.05)$, so that the compensation variable has an effect on employee performance at PTPN X Kebun Ajung Gayasan Jember. The R square value of 0.719 means that the magnitude of the influence of the independent variable on the dependent variable is $71.9 \%$ and the remaining $28.1 \%$.

Keywords: Job Training, Work Environment, Compensation, And Employee Performance.

\section{Pendahuluan}

Setiap perusahaan, baik perusahaan kecil maupun perusahaan besar memiliki keinginan untuk melakukan kemajuan dalam menjalankan usahanya, baik itu dari segi kemudahan maupun tingkat pencapaian hasil. Perkembangan dan perluasan yang dilakukan oleh perusahaan harus didukung oleh sarana dan prasarana yang memadai 
agar semua perencanaan yang dilakukan dapat terlaksana dengan baik dan mendapatkan hasil yang memuaskan. Hal ini menuntut perusahaan mencari alternatif-alternatif jitu untuk mendukung apa yang dicita-citakan, seperti dibutuhkankannya solusi, inovasi dan strategi apa yang harus diambil oleh pimpinan.

Sumber daya manusia menjadi salah satu faktor internal yang memegang peranan penting dalam menentukan berhasil atau tidaknya suatu organisasi dalam mencapai tujuan. Organisasi yang memiliki sumber daya manusia yang berkualitas maka organisasi tersebut akan menjadi suatu organisasi yang mampu bersaing, dan unggul karena akan menghasilkan kinerja tinggi. Sumber daya manusia merupakan sumber daya terpenting yang dimiliki oleh suatu organisasi, salah satu implikasinya adalah bahwa investasi terpenting yang mungkin dilakukan oleh suatu organisasi adalah di bidang sumber daya manusia (Abdurrahmat, 2006). Usaha untuk memperoleh sumber daya manusia yang berkualitas maka dibutuhkan pendidikan, karena pendidikan dianggap mampu menghasilkan tenaga kerja yang bermutu tinggi, mempunyai pola pikir dan cara bertindak yang modern. Sumber daya manusia seperti inilah yang diharapkan mampu menggerakkan roda pembangunan ke depan.

Selain kualitas karyawan, Kondisi lingkungan kerja yang baik juga salah satu faktor penunjang produktivitas karyawan yang pada akhirnya berdampak pada kenaikan tingkat kinerja karyawan. Kondisi lingkungan kerja dapat dibagi menjadi 2 (dua) yaitu Kompensasi dan lingkungan kerja non-fisik (Wirawan, 2009). Contoh Kompensasi adalah penerangan, warna dinding, sirkulasi udara, musik, kebersihan, dan keamanan. Sedangkan lingkungan kerja non-fisik contohnya adalah struktur tugas, desain pekerjaan, pola kerja sama, pola kepemimpinan, dan budaya organisasi.

Adanya pembagian mengenai lingkungan kerja tersebut tidak dapat dipisahkan satu sama lain. Antara keduanya harus saling seimbang, karena baik Kompensasi maupun non-fisik sama-sama memengaruhi kinerja karyawan. Untuk menyeimbangkan keduanya diperlukan kesadaran pihak manajemen dari perusahaan tersebut. Oleh sebab itu, diperlukan lingkungan kerja yang kondusif untuk menunjang kinerja karyawan dalam melaksanakan pekerjaannya, agar hasil kerja yang diperoleh dapat tercapai secara optimal. Berbagai jenis pelatihan guna untuk meningkatkan kemampuan karyawan. Pemerataan proses pelatihan juga diperlukan agar tidak terjadi ketimpangan antar karyawan. Hasil penelitian (Ansori, 2018), (Elizar, Elizar \& Tanjung, 2018), dan (Permana, 2015) yang menyatakan Pelatihan, kompensasi dan lingkungan kerja berpengaruh positif dan signifikan terhadap kinerja karyawan.

Sebagai perusahaan BUMN yang bergerak dibidang perkebunan, PT. Perkebunan Nusantara X Ajung adalah Unit Usaha Tembakau, dari PT. Perkebunan Nusantara X yang terletak di Ajung, Jember untuk memproduksi dan mengekspor tembakau cerutu yang terdiri dari Tembakau Na Oogst (Besuki \& Vorstenlanden) dan Tembakau Bawah Naungan (TBN). Sebagai salah satu agen ekspor utama di Indonesia, PT. Perkebunan Nusantara X Ajung berkontribusi pada pemasukan devisa negara. dengan penargetan pangsa pasar domestic dan internasional, produk yang dihasilkan haruslah memenuhi 
standar dari pasar internasional. Dengan adanya sumber daya manusia yang memenuhi kriteria dapat menghasilkan produk yang berkualitas.

Tabel Rekap Usulan Kenaikan Grade Atas Penilaian Kinerja

\begin{tabular}{clc}
\hline No & \multicolumn{1}{c}{ Bagian } & Jumlah \\
\hline $\mathbf{1}$ & Tanaman Tbn I & 4 \\
$\mathbf{2}$ & Tanaman Tbn II & 3 \\
$\mathbf{3}$ & Tanaman Tbn II & 5 \\
$\mathbf{4}$ & Tanaman Tbn IV & 6 \\
$\mathbf{5}$ & Tanaman Tbn V & 3 \\
$\mathbf{6}$ & Tanaman Tbn VI & 4 \\
$\mathbf{7}$ & Tanaman Tbn VII & 4 \\
$\mathbf{8}$ & Tanaman Tbn VIII & 6 \\
$\mathbf{9}$ & Tanaman Tbn IX & 5 \\
$\mathbf{1 0}$ & Tanaman Tbn X & 3 \\
$\mathbf{1 1}$ & Tanaman & 17 \\
$\mathbf{1 2}$ & Pengolahan & 18 \\
\hline
\end{tabular}

Berdasarkan tabel 1 hanya sebagian kecil dari karyawan yang dapat kenaikan grade atau golongan yakni sebesar $24 \%$ dari total keseluruhan. Hal ini menunjukkan kurangnya kemampuan karyawan dalam pemenuhan kriteria kinerja yang berlaku.

Dari fenomena diatas yang telah dijabarkan maka peneliti mencoba mengangkat variabel yang terdiri dari pelatihan kerja, lingkungan kerja, kompensasi yang dikira dapat menciptakan kinerja karyawan yang lebih baik. Salah satu variabel pelatihan kerja sebagai salah satu pendorongnya agar kinerja karyawan lebih baik kedepannya.

\section{Metode}

Identifikasi Variabeli

Dalam penelitian ini terdapat dua variabel, yaitu Variabel Independen $(X)$, Pelatihan Kerja (X1), Lingkungan Kerja (X2), Kompensasi (X3), Variabel Dependen (Y) adalah Kinerja Karyawan

Desain Penelitian

Desaian penelitian ini menggunakan penelitian deskriptif

Jenis Data Penelitian

Data Primer yang digunakan dalam penelitian ini diperoleh dari hasil penyebaran kuisioner yang disebarkan secara langsung kepada karyawan PT. Perkebunan Nusantara $X$ Ajung. Hasil kuesioner di rekap ke software Microsoft Excel, kemudian diolah ke SPSS versi 22.

Data sekunder Dalam penelitian ini data rekap tenaga kerja dan data Rekap Usulan Kenaikan Grade Atas Penilaian Kinerja yang diambil dari PT. Perkebunan Nusantara X Ajung Kebun Ajong Gayasan. 
Populasi dan Sampel

Populasi dari penelitian ini adalah karyawan pada PT. Perkebunan Nusantara $X$ Ajung yang berjumlah 330 orang. Mengingat besarnya jumlah populasi dalam penelitian ini, dan peneliti tidak mungkin mempelajari semua yang ada pada populasi, misalnya karena keterbatasan dana, tenaga dan waktu. Maka peneliti dapat menggunakan sampel yang diambil dari populasi tersebut Jumlah sampel yang akan diambil menggunakan rumus Slovin yaitu sebagai berikut:

$$
\begin{array}{ll}
n=\frac{330}{1+330(0,1)} & \text { Keterangan } \\
n=\frac{330}{1+3,3} & \mathrm{n}=\text { Ukuran Sampel } \\
n=\frac{\mathrm{N}=\text { Ukuran Populasi }}{330} & \mathrm{E}=\text { Tingkat Kesalahan } \\
n=\begin{array}{c}
4,3 \\
=76
\end{array} &
\end{array}
$$

\section{Keterangan}

Sehingga sampel yang digunakan adalah 76 sampel dari 330 populasi.

Teknik Pengambilan Sampel

Kriteria responden dalam penelitian ini adalah:

1. Responden yang berusia minimal 21 tahun dan maksimal 50 tahun.

2. Responden merupakan karyawan yang bekerja minimal 2 tahun.

3. Berdasarkan jenis kelamin

\section{Teknik Pengumpulan Data}

Pengumpulan data penelitian dilakukan dengan cara pengisian kuisioner, wawancara, observasi, dan kepustakaan untuk memperoleh data primer, sesuai dengan tujuan penelitian. Peneliti menemui responden secara langsung, tentunya sesuai dengan peraturan dan tidak mengganggu kelangsungan proses kerja diperusahaan. Metode yang digunakan pada pengumpulan data ini adalah:

1. Wawancara

2. Observasi

3. Kepustakaan

4. Kuesioner

Uji Validitas dan Uji Reliabilitas
1. Uji Validitas
2. Uji Reliabilitas

Uji RegresiiLinieriBerganda

Model regresi linier dengan rumus sebagai berikut:

Rumus $=Y=a+b 1 X 1+b 2 X 2+b 3 X 3+e$

Keterangan: 
$\mathrm{Y}=$ Kinerja Karyawan a

$\mathrm{A}=$ Konstanta

$\mathrm{X} 1=$ Variabel Pelatihan Kerja

$\mathrm{X} 2=$ Variabel Lingkungan Kerja

X3= Variabel Kompensasi

b1 $=$ Koefisien Regresi dari Pelatihan Kerja

b2= Koefisien Regresi dari Lingkungan Kerja

b3= Koefisien Regresi dari Kompensasi

$\mathrm{e}=$ Standard Error

Uji Asumsi Klasik

1. Uji Normalitas

2. Uji Multikolonearitas

3. Uji Heteroskedastisitas

\section{Hasil dan Pembahasan}

Tabel 2. Uji Validitas

\begin{tabular}{ccccccc}
\hline & Variabel/Indikator & \multicolumn{2}{c}{ Kriteria 1} & \multicolumn{2}{c}{ Kriteria 2} & \\
\cline { 2 - 5 } No & Pelatihan Kerja & r hitung & r tabel & Nilai sig & alpha & Keterangan \\
1 & X1.1 & 0,818 & 0.2257 & 0,000 & 0,05 & Valid \\
2 & X1.2 & 0,840 & 0.2257 & 0,000 & 0,05 & Valid \\
3 & X1.3 & 0,723 & 0.2257 & 0,000 & 0,05 & Valid \\
\cline { 5 - 6 } & & & & & & \\
\hline & Lingkungan Kerja & & & & & \\
2 & X2.1 & 0,455 & 0.2257 & 0,000 & 0,05 & Valid \\
3 & X2.2 & 0,445 & 0.2257 & 0,000 & 0,05 & Valid \\
4 & X2.3 & 0,474 & 0.2257 & 0,000 & 0,05 & Valid \\
5 & X2.4 & 0,416 & 0.2257 & 0,000 & 0,05 & Valid \\
6 & X2.5 & 0,358 & 0.2257 & 0,002 & 0,05 & Valid \\
7 & X2.6 & 0,257 & 0.2257 & 0,000 & 0,05 & Valid \\
8 & X2.7 & 0,509 & 0.2257 & 0,000 & 0,05 & Valid \\
9 & X2.8 & 0,226 & 0.2257 & 0,000 & 0,05 & Valid \\
10 & X2.9 & 0,386 & 0.2257 & 0,000 & 0,05 & Valid \\
& X2.10 & 0,483 & 0.2257 & 0,000 & 0,05 & Valid \\
\hline
\end{tabular}

\begin{tabular}{|c|c|c|c|c|c|c|}
\hline & mpen & & & & & \\
\hline 1 & X3.1 & 0,609 & 0.2257 & 0,000 & 0,05 & Valid \\
\hline 2 & X3.2 & 0,687 & 0.2257 & 0,000 & 0,05 & Valid \\
\hline 3 & X3.3 & 0,651 & 0.2257 & 0,000 & 0,05 & Valid \\
\hline 4 & X3.4 & 0,548 & 0.2257 & 0,000 & 0,05 & Valid \\
\hline
\end{tabular}




\begin{tabular}{ccccccc}
\cline { 2 - 5 } & Kinerja Karyawan & & & & & \\
1 & Y.1 & 0,695 & 0.2257 & 0,000 & 0,05 & Valid \\
2 & Y.2 & 0,623 & 0.2257 & 0,000 & 0,05 & Valid \\
3 & Y.3 & 0,494 & 0.2257 & 0,000 & 0,05 & Valid \\
4 & Y.4 & 0,650 & 0.2257 & 0,000 & 0,05 & Valid \\
5 & Y.5 & 0,605 & 0.2257 & 0,000 & 0,05 & Valid \\
6 & Y.6 & 0,506 & 0.2257 & 0,000 & 0,05 & Valid
\end{tabular}

Tabel 3. Uji Reliabilitas

\begin{tabular}{clccc}
\hline No & \multicolumn{1}{c}{ Variabel } & Alpha hitung & Standar alpha & Keterangan \\
\hline 1 & Pelatihan Kerja $\left(\mathrm{X}_{1}\right)$ & 0,704 & 0,60 & Reliabel \\
2 & Lingkungan Kerja $\left(\mathrm{X}_{2}\right)$ & 0,712 & 0,60 & Reliabel \\
3 & Kompensasi $\left(\mathrm{X}_{3}\right)$ & 0,679 & 0,60 & Reliabel \\
4 & Kinerja Karyawan $(\mathrm{Y})$ & 0,640 & 0,60 & Reliabel
\end{tabular}

Berdasarkan tabel 3 dapat diketahui persamaan regresi yang terbentuk adalah:

$\mathrm{Y}=\mathbf{3}, 636+0,662 \mathrm{X} 1+0,304 \times 2+0,481 \times 3$

1. Dari persamaan tersebut dapat diartikan bahwa:

2. Konstanta $=3,636$ menunjukkan besaran kinerja karyawan 3,636 satuan pada saat Pelatihan Kerja, Lingkungan Kerja, dan Kompensasi sama dengan nol.

3. $\beta 1=0,662$ artinya meningkatnya Pelatihan Kerja per 0,662 satuan akan meningkatkan kinerja karyawan apabila Lingkungan Kerja, dan Kompensasi sama dengan nol. Hal ini juga mengindikasikan bahwa Pelatihan Kerja berpengaruh positif terhadap kinerja karyawan yang berarti semakin baik Pelatihan Kerja akan berdampak pada semakin baik pula kinerja karyawan dengan asumsi Lingkungan Kerja, dan Kompensasi konstan.

4. $\beta 2=0,304$ artinya meningkatnya Lingkungan Kerja per 0,304 satuan akan meningkatkan kinerja karyawan apabila Pelatihan Kerja, dan Kompensasi sama dengan nol. Hal ini juga mengindikasikan bahwa Lingkungan Kerja berpengaruh positif terhadap kinerja karyawan yang berarti semakin baik Lingkungan Kerja akan berdampak pada semakin ringginya kinerja karyawan dengan asumsi Pelatihan Kerja, dan Kompensasi konstan.

5. $\beta 3=0,481$ artinya meningkatnya Kompensasi per 0,481 satuan akan meningkatkan kinerja karyawan apabila Pelatihan Kerja, dan Lingkungan Kerja sama dengan nol. Hal ini juga mengindikasikan bahwa Kompensasi berpengaruh positif terhadap kinerja karyawan yang berarti semakin baik kinerja karyawan akan berdampak pada semakin baik pula kompensasi dengan asumsi Pelatihan Kerja, dan Lingkungan Kerja konstan. 


\section{Gambar 1. Uji Normalitas}

Berdasarkan gambar 1 setelah dilakukan pengujian ternyata semua data terdistribusi secara normal, sebaran data berada di sekitar garis diagonal. Hal ini menunjukkan bahwa model regresi dalam penelitian ini memenuhi asumsi normalitas.

Tabel 4. Uji Multikolonieritas

\begin{tabular}{clcc}
\hline No & \multicolumn{1}{c}{ Variabel } & Nilai Tolerance & Nilai VIF \\
\hline $\mathbf{1}$ & Pelatihan Kerja $\left(\mathrm{X}_{1}\right)$ & 0,867 & 1,228 \\
$\mathbf{2}$ & Lingkungan Kerja $\left(\mathrm{X}_{2}\right)$ & 0,754 & 1,326 \\
$\mathbf{3}$ & Kompensasi $\left(\mathrm{X}_{3}\right)$ & 0,737 & 1,356 \\
\hline
\end{tabular}

Tabel 4 menunjukkan bahwa nilai VIF semua variabel bebas dalam penelitian ini lebih kecil dari 10 sedangkan nilai toleransi semua variabel bebas lebih dari $10 \%$ yang berarti tidak terjadi kolerasi antar variabel bebas yang nilainya lebih dari $90 \%$, dengan demikian dapat disimpulkan bahwa tidak terdapat gejala multikolinearitas antar variabel bebas dalam model regresi.

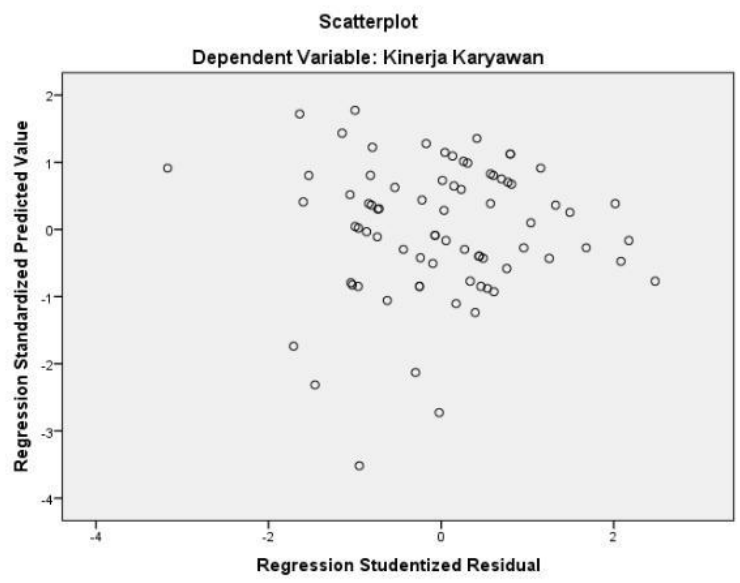

Gambar 2. Uji Heteroskedastisitas

Dari hasil uji heterokedastisitas yang telah dilakukan ternyata titik-titik menyebar secara acak, tidak membentuk suatu pola tertentu yang jelas, serta tersebar baik di atas maupun di bawah angka 0 (nol) pada sumbu $Y$, hal ini berarti tidak terjadi penyimpangan asumsi klasik heterokedastisitas pada model regresi yang dibuat, dengan kata lain menerima hipotesis homoskedastisitas.

\section{Tabel 5. Hasil Uji t}

No

Uji t

Keterangan

$\begin{array}{ccccc}\text { Variabel } & \begin{array}{c}\text { Signifika } \\ \text { nsi }\end{array} & \begin{array}{c}\text { Taraf } \\ \text { Signifik }\end{array} & t_{\text {hitung }} & t_{\text {tabel }} \\ & & & \end{array}$




$\begin{array}{llccrrr} & \text { Hitung } & \text { ansi } & & & \\ \mathbf{1} & \begin{array}{l}\text { Pelatihan } \\ \text { Kerja }\end{array} & 0,000 & 0,05 & 6,358 & 1,6663 & \text { Signifikan } \\ \mathbf{2} & \begin{array}{l}\text { Lingkungan } \\ \text { Kerja }\end{array} & 0,000 & 0,05 & 4,807 & 1,6663 & \text { Signifikan } \\ \mathbf{3} & \text { Kompensasi } & 0,000 & 0,05 & 4,694 & 1,6663 & \text { Signifikan }\end{array}$

Dari tabel 5 dapat di ketahuai perbandingan antara taraf signifikansi dengan signifikansi tabel adalah sebagai berikut:

a. Hasil uji Pelatihan Kerja mempunyai nilai signifikansi hitung sebesar 0,000 dan lebih kecil dari 0,05 dan $t$ hitung $(6,358)>t$ tabel $(1,6663)$ yang berarti bahwa hipotesis Pelatihan Kerja mempunyai pengaruh terhadap kinerja karyawan diterima. Hal ini juga menunjukkan bahwa Pelatihan Kerja mempengaruhi kinerja karyawan yang berarti semakin baik Pelatihan Kerja akan berdampak pada semakin tinggi kinerja karyawan.

b. Hasil uji Lingkungan Kerja mempunyai nilai signifikansi sebesar 0,000 dan lebih besar dari 0,05 dan t hitung $(4,807)>t$ tabel $(1,6663)$ yang berarti bahwa hipotesis Lingkungan Kerja mempunyai pengaruh terhadap kinerja karyawan diterima. Hal ini juga menunjukkan bahwa Lingkungan Kerja mempengaruhi kinerja karyawan yang berarti semakin baik Lingkungan Kerja akan berdampak pada semakin tinggi kinerja karyawan.

c. Hasil uji Kompensasi mempunyai nilai signifikansi sebesar 0,000 dan lebih besar dari 0,05 dan $\mathrm{t}$ hitung $(4,694)>\mathrm{t}$ tabel $(1,6663)$ yang berarti bahwa hipotesis Kompensasi mempunyai pengaruh terhadap kinerja karyawan diterima. Hal ini juga menunjukkan bahwa Kompensasi mempengaruhi kinerja karyawan yang berarti semakin baik Kompensasi akan berdampak pada semakin tinggi kinerja karyawan.

Tabel 6. Koefisien Determinasi $\left(\mathbf{R}^{2}\right)$

\begin{tabular}{|c|c|c|}
\hline No & Kriteria & Koefisien \\
\hline 1 & $R$ & 0,854 \\
\hline 2 & R Square & 0,730 \\
\hline 3 & Adjusted $R$ Square & 0,719 \\
\hline
\end{tabular}

Hasil perhitungan regresi Tabel 6 dapat diketahui bahwa koefisien determinasi yang diperoleh sebesar 0,719. Hal ini berarti 71,9\% variasi variabel kinerja karyawan dapat dijelaskan oleh Pelatihan Kerja, Lingkungan Kerja, dan Kompensasi, sedangkan sisanya sebesar 0,281 atau 28,1\% diterangkan oleh variabel lain yang tidak diajukan dalam penelitian ini.

Berdasarkan hasil pengujian secara statistik, penjelasan dari masing-masing pengaruh variabel dijelaskan sebagai berikut:

1. Pengaruh secara parsial Pelatihan Kerja terhadap kinerja karyawan. 
Hasil uji Pelatihan Kerja mempunyai nilai signifikansi hitung sebesar 0,000 dan lebih kecil dari 0,05 dan $t$ hitung $(6,358)>t$ tabel $(1,6663)$ yang berarti bahwa hipotesis Pelatihan Kerja mempunyai pengaruh terhadap kinerja karyawan diterima. Hal ini juga menunjukkan bahwa Pelatihan Kerja mempengaruhi kinerja karyawan yang berarti semakin baik Pelatihan Kerja akan berdampak pada semakin tinggi kinerja karyawan. Hasil penelitian ini sejalan dengan penelitian yang dilakukan oleh (Ansori, 2018) yang menyatakan bahwa pelatihan kerja berpengaruh positif dan signifikan terhadap kinerja karyawan.

2. Pengaruh secara parsial Lingkungan Kerja terhadap kinerja karyawan.

Hasil uji Lingkungan Kerja mempunyai nilai signifikansi sebesar 0,000 dan lebih besar dari 0,05 dan $t$ hitung $(4,807)>t$ tabel $(1,6663)$ yang berarti bahwa hipotesis Lingkungan Kerja mempunyai pengaruh terhadap kinerja karyawan diterima. Hal ini juga menunjukkan bahwa Lingkungan Kerja mempengaruhi kinerja karyawan yang berarti semakin baik Lingkungan Kerja akan berdampak pada semakin tinggi kinerja karyawan. Hasil ini mendukung teori Keith Devis yang menyatakan Lingkungan Kerja sebagai pelaksana manajemen yang digunakan untuk memperteguh pedoman-pedoman organisasi. Hasil ini juga mendukung penelitian sebelumnya oleh (Ansori, 2018), (Elizar, Elizar \& Tanjung, 2018), dan (Permana, 2015) yang menyatakan ada pengaruh Lingkungan Kerja terhadap kinerja karyawan dan sesuai dengan hipotesis yang diajukan, yaitu Lingkungan Kerja berpengaruh terhadap kinerja karyawan.

3. Pengaruh secara parsial Kompensasi terhadap kinerja karyawan.Hasil uji Kompensasi mempunyai nilai signifikansi sebesar 0,000 dan lebih besar dari 0,05 dan $t$ hitung $(4,694)>t$ tabel $(1,6663)$ yang berarti bahwa hipotesis Kompensasi mempunyai pengaruh terhadap kinerja karyawan diterima. Hal ini juga menunjukkan bahwa Kompensasi mempengaruhi kinerja karyawan yang berarti semakin baik Kompensasi akan berdampak pada semakin tinggi kinerja karyawan. Hasil ini juga sejalan dengan penelitian yang dilakukan oleh (Ansori, 2018), (Elizar, Elizar \& Tanjung, 2018), dan (Permana, 2015) yang menyatakan ada pengaruh Kompensasi terhadap kinerja karyawan dan sesuai dengan hipotesis yang diajukan, yaitu Kompensasi berpengaruh terhadap kinerja karyawan. 


\section{Simpulan}

Dari pengujian secara statistik yang telah dilakukan, maka dapat ditarik kesimpulan sebagai berikut:

1. Hasil uji Pelatihan Kerja mempunyai nilai signifikansi hitung sebesar 0,000 dan lebih kecil dari 0,05 dan $t$ hitung $(6,358)>t$ tabel $(1,6663)$ yang berarti bahwa hipotesis Pelatihan Kerja mempunyai pengaruh terhadap kinerja karyawan diterima. Hal ini juga menunjukkan bahwa Pelatihan Kerja mempengaruhi kinerja karyawan yang berarti semakin baik Pelatihan Kerja akan berdampak pada semakin tinggi kinerja karyawan.

2. Hasil uji Lingkungan Kerja mempunyai nilai signifikansi sebesar 0,000 dan lebih besar dari 0,05 dan $t$ hitung $(4,807)>t$ tabel $(1,6663)$ yang berarti bahwa hipotesis Lingkungan Kerja mempunyai pengaruh terhadap kinerja karyawan diterima. Hal ini juga menunjukkan bahwa Lingkungan Kerja mempengaruhi kinerja karyawan yang berarti semakin baik Lingkungan Kerja akan berdampak pada semakin tinggi kinerja karyawan.

3. Hasil uji Kompensasi mempunyai nilai signifikansi sebesar 0,000 dan lebih besar dari 0,05 dan $t$ hitung $(4,694)>t$ tabel $(1,6663)$ yang berarti bahwa hipotesis Kompensasi mempunyai pengaruh terhadap kinerja karyawan diterima. Hal ini juga menunjukkan bahwa Kompensasi mempengaruhi kinerja karyawan yang berarti semakin baik Kompensasi akan berdampak pada semakin tinggi kinerja karyawan.

\section{Daftar Pustaka}

Abdurrahmat, F. (2006). Manajemen Sumder Daya Manusia. Bandung: Rineka Cipta.

Ansori, S. (2018). Pengaruh Lingkungan Kerja, Lingkungan dan Kompensasi Finansial Terhadap Kinerja Karyawan Bagian Administrasi dan Keuangan PTPN XI PG Waringin Anom Kabupaten Situbondo. Jember: Universitas Jember.

Elizar, Elizar \& Tanjung, H. (2018). Pengaruh Pelatihan, Kompetensi, Lingkungan Kerja terhadap Kinerja Pegawai. Maneggio: Jurnal Ilmiah Magister Manajemen, 1(1), 46-58. https://doi.org/10.30596/maneggio.v1i1.2239

Permana, D. (2015). Pengaruh Kualitas Kehidupan Kerja Dan Lingkungan Kerja Terhadap Disiplin Kerja (Studi pada Karyawan PT. Bank Negara Indonesia (Persero) Kantor Cabang Utama Malang). Jurnal Administrasi Bisnis S1 Universitas Brawijaya, 26(2), 86300

Wirawan. (2009). Evaluasi Kinerja Sumber Daya Manusia Teori Aplikasi dan Penelitian. Jakarta: Salemba Empat. 